\title{
Distributions of rare earths and heavy metals in field-grown maize after application of rare earth-containing fertilizer
}

\author{
Xingkai Xu ${ }^{\mathrm{a}, \mathrm{b}, *}$, Wangzhao Zhu ${ }^{\mathrm{c}}$, Zijian Wang ${ }^{\mathrm{a}}$, Geert-Jan Witkamp \\ ${ }^{a}$ State Key Laboratory of Environmental Aquatic Chemistry, Research Center for Eco-Environmental Sciences, \\ Chinese Academy of Sciences, Beijing, 100085 PR China \\ ${ }^{\mathrm{b}}$ State Key Laboratory of Atmospheric Boundary Layer Physics and Atmospheric Chemistry, Institute of Atmospheric Physics, \\ Chinese Academy of Sciences, Beijing, 100029 PR China \\ ${ }^{c}$ Laboratory for Process Equipment, Technical University of Delft, 2628 CA, Delft, The Netherlands
}

Received 7 January 2001; accepted 30 November 2001

\begin{abstract}
Rare earths are widely applied in Chinese agriculture to improve crop nutrition through the use of fertilizers, yet little is known of their accumulation in field-grown crops. We have studied the distribution of 16 rare earths (Sc, Y and 14 lanthanide elements) in field-grown maize and the concentration of heavy metals in the grains after application of rare earth-containing fertilizer. When maize entered the vigorous vegetation growth stage (e.g. early stemelongation stage), rare earth-containing fertilizer was applied to the soil with irrigation water. At 10 days after application of the rare earths, significantly dose-dependent accumulative effects of individual rare earth concentrations in the roots and the plant tops of maize were observed, with the exception of Sc and Lu. At the level of $2 \mathrm{~kg}$ rare earths $\mathrm{ha}^{-1}$, accumulative concentrations of most light rare earths (e.g. $\mathrm{La}, \mathrm{Ce}, \mathrm{Pr}$ and $\mathrm{Nd}$ ) and $\mathrm{Gd}$ in the plant tops were much larger than those in the control. Concentrations of individual rare earths in a field-grown maize after application of rare earths decreased in the order of root $\gg$ leaf $>$ stem $>$ grain. During the maize growth period, selective accumulation of individual rare earths (e.g. La, Ce) in the roots seemed to be in dynamic equilibrium, and the distribution of these elements in the plant tops was variable. At a dosage of less than $10 \mathrm{~kg}$ rare earths ha ${ }^{-1}$, no apparent accumulative concentrations of individual rare earths appeared in the maize grains. Under the experimental conditions, application of rare earth-containing fertilizer did not induce an increase in the concentrations of heavy metals in the grains. We conclude that the present dosage of rare earths $\left(<0.23 \mathrm{~kg} \mathrm{ha}^{-1}\right.$ year $\left.^{-1}\right)$ currently applied in China can hardly affect the safety of maize grains in arable soil, even over a long period. (C) 2002 Elsevier Science B.V. All rights reserved.
\end{abstract}

Keywords: Dose-dependent accumulation; Heavy metals; Maize; Rare earths; Rare earth-containing fertilizer

\footnotetext{
*Corresponding author. Present address: LAPC, Institute of Atmospheric Physics, Chinese Academy of Sciences, Beijing, 100029 PR China. Fax: + 86-10-62041393.

E-mail address: xingkai_xu@hotmail.com (X. Xu).
} 


\section{Introduction}

China contains approximately $80 \%$ of the world's resource of rare earths and is a major producer of them for the world market (Brown et al., 1990). Considerable work has shown that the application of rare earths with suitable dosages can improve crop growth and production, as well as resistance to poor growing conditions (Guo, 1988; Brown et al., 1990; Xu, 1997). The beneficial effects may be due to the stimulatory effects of these elements on nutrient uptake by plants or the increased synthesis of chlorophyll in the plant (Guo, 1988; Wang, 1988; Qi et al., 1990). As a result, rare earths are now widely used in increasing quantities by Chinese agriculturists ( $\mathrm{Yu}$ and Chen, 1995; Xu, 1997; Wen et al., 2000).

The widespread application of rare earths has led to scattering and bio-accumulation in the environment, particularly in agricultural production, which leads to transfer through the food chain to the human body. Velasco et al. (1979) suggested that, at high dosages, rare earths might become harmful in the environment. It has been predicted that the industrial and agricultural utilization of rare earths and the resulting environmental contamination will rapidly grow in the next few decades (Volokh et al., 1990).

Rare earths can be taken up through the leaf surface after spraying (Sun et al., 1994), but normally uptake exclusively takes place via the roots. Concentrations of rare earths in plants seem to be extremely variable, and are dependent on the various species of plants and their corresponding habitat (Ichihashi et al., 1992; Wyttenbach et al., 1998). Plants growing on the rare earth-enriched soil show very high concentrations (Miekeley et al., 1994). A body of literature has reported the distribution patterns of rare earths in native plants (Henke, 1977; Ichihashi et al., 1992; Miekeley et al., 1994; Wang, et al., 1997; Wyttenbach et al., 1998). In addition, some data are available on the distribution of rare earths in field-grown crops after foliage dressing with fertilizer containing small amounts of rare earths (Zhang et al., 1993; Liu et al., 1997; Wang et al., 2001). Such an application with low dosage, however, does not allow quantification of the accumulative effects of rare earths in the crops as a function of high doses. Since, up to now, Chinese agriculturists have used rare earth-containing fertilizers as base fertilizers together with $\mathrm{N}$ fertilizers (Xu, 1997; Wen et al., 2000), currently studies are only available on the combined effects of nitrogen and lanthanides (Xu and Wang, 2001). In addition, very little attention has been paid to the concentrations of heavy metals in the grains after years of application. In a literature survey, there were no data available on the dose-dependent accumulation of individual rare earths in field-grown crops, which is a key to assess the exposure to rare earths through agricultural application.

This paper describes a field study on the dosedependent distribution and translocation of rare earths in maize after application of rare earthcontaining fertilizer. Of particular interest was to investigate the accumulation of rare earths and heavy metals in the maize grains, which is important to assess the potential safety effects of rare earths after years of agricultural application.

\section{Materials and methods}

\subsection{Rare earth-containing fertilizer}

The rare earth-containing fertilizer used in this study is a commercial product for agricultural utilization and was supplied by Research Center for Agricultural Application of Rare Earth Elements in China. It is a mixture of rare earths as their nitrates. Normally, this mixture is made by extracting the rare earths from their ores using nitric acid, and more than $60 \%$ in this fertilizer is thus in nitrate form and is soluble (Brown et al., 1990). Concentrations of individual rare earths and heavy metals in this fertilizer were measured by HR-ICPMS and are listed in Tables 1 and 2.

\subsection{Field experiment}

The field site used in this study is located in Changping County of Beijing, China, which is used as an agricultural district. The crop investigated in this study was maize. The soil tested belongs to a luvisol according to FAO taxonomy (FAO, 1982). This type of soil represents one of 
Table 1

Concentration of individual rare earths in the rare earth-containing fertilizer

\begin{tabular}{lc}
\hline Element & $\begin{array}{c}\text { Concentration } \\
\left(\mathrm{g} \mathrm{kg}^{-1} \text { dry wt. }\right)\end{array}$ \\
\hline $\mathrm{Y}$ & 0.1 \\
$\mathrm{La}$ & 15.4 \\
$\mathrm{Ce}$ & 24.1 \\
$\mathrm{Pr}$ & 11.8 \\
$\mathrm{Nd}$ & 1.1 \\
$\mathrm{Sm}$ & 2.0 \\
$\mathrm{Eu}$ & 0.2 \\
$\mathrm{Gd}$ & 1.1 \\
& $\left(\mathrm{mg} \mathrm{kg} \mathrm{g}^{-1}\right.$ dry wt. $)$ \\
$\mathrm{Tb}$ & 25.8 \\
$\mathrm{Dy}$ & 91.6 \\
$\mathrm{Ho}$ & 4.3 \\
$\mathrm{Er}$ & 26.9 \\
$\mathrm{Tm}$ & 1.4 \\
Yb & 5.3 \\
Lu & 0.5 \\
Total LREs & 64.1 \\
Total HREs & 1.2 \\
Total MREs & 3.4 \\
\hline
\end{tabular}

Total LREs, total concentration of light rare earths (from La to Eu); Total HREs, total concentration of heavy rare earths (from $\mathrm{Gd}$ to $\mathrm{Lu}$ ); Total MREs, total concentration of medium rare earths (from $\mathrm{Sm}$ to $\mathrm{Ho}$ ). The same also holds for the following tables.

the major soil types in middle parts of China where rare earths have been intensively applied. The physical and chemical properties of the soil were measured according to methods described by Kim (1995) and are listed in Table 3. Background concentrations of rare earths in the soil were measured by HR-ICP-MS (John et al., 1998) and are listed in Table 4.

This field experiment contained five treatments with different dosages, with four replicates for each treatment. Hence, the experiment had 20 subzones, with an area of $4.4 \times 4.4 \mathrm{~m}^{2}$ each. Each sub-zone was separated from the other zones by strips of $1.2 \mathrm{~m}$ in width to minimize cross-contamination among different treatments. All treatments were arranged according to the method of a directcross design.

The fertilizer was dissolved in irrigation water ( $\mathrm{pH}$ 6.0) and was then applied to sub-zones 45 days after sowing, when maize entered the vigor-
Table 2

Concentration of heavy metals in the rare earth-containing fertilizer

\begin{tabular}{|c|c|c|c|c|c|c|c|c|}
\hline \multicolumn{9}{|c|}{ Concentration (mg kg ${ }^{-1}$ dry wt.) } \\
\hline $\mathrm{Ca}$ & $\mathrm{Cr}$ & Mn & Co & $\mathrm{Ni}$ & $\mathrm{Zn}$ & $\mathrm{Cu}$ & Mo & $\mathrm{Pb}$ \\
\hline 1323.1 & 16.5 & 92.7 & 3.5 & 29.4 & 118.7 & 34.4 & 1.8 & 426.5 \\
\hline
\end{tabular}

ous growth stage (e.g. early stem-elongation stage). The dosage of the rare earths applied was at $0,2,10,20$ and $100 \mathrm{~kg}$ rare earths ha ${ }^{-1}$, added as a solution of the same volume containing rare earths (approx. $150 \mathrm{ml}$ ) around each plant in any sub-zone. The amount of $\mathrm{N}$ added as urea in the solution was the same in all treatments to avoid side effects of $\mathrm{N}$ in the rare earth-containing fertilizer.

\subsection{Plant sampling}

Prior to application of rare earth-containing fertilizer, maize plants in each sub-zone were harvested to compare the homogeneity of rare earth concentrations in all the plants. Each plant sample was divided into the roots and the plant top.

At 10 days after the application of rare earths and at the maturity stage (more than 2 months after application), plant samples were again collected according to an ' $S$ ' curve in each sub-zone. The samples after 10 days were divided into the roots and the plant tops. The samples at maturity stage were segmented into the roots, stems, leaves and grains. All plant samples were washed in the

Table 3

Main physical and chemical properties of the soil tested

\begin{tabular}{lc}
\hline Sand $\left(\mathrm{g} \mathrm{kg}^{-1}\right.$ soil) & 240 \\
Silt $\left(\mathrm{g} \mathrm{kg}^{-1}\right.$ soil) & 420 \\
Clay $\left(\mathrm{g} \mathrm{kg}^{-1}\right.$ soil) & 340 \\
CEC (cmol kg-1) & 19.8 \\
$\mathrm{pH}\left(\mathrm{soil} / \mathrm{water}^{-1: 5)}\right.$ & 7.25 \\
Soil bulk density $\left(\mathrm{mg} \mathrm{m}^{-3}\right)$ & 1.31 \\
Total C (mg kg-1) & 14500 \\
Total N (mg kg & 980 \\
Available N (mg kg-1) & 67.5 \\
Total P (mg kg & 8600 \\
Available P $\left(\mathrm{mg} \mathrm{kg}^{-1}\right)$ & 72.5 \\
\hline
\end{tabular}


Table 4

Background concentrations of individual rare earths in the soil tested

\begin{tabular}{|c|c|c|c|c|c|c|c|c|c|c|c|c|c|c|c|c|c|}
\hline \multicolumn{18}{|c|}{ Concentration ( $\mathrm{mg} \mathrm{kg}^{-1}$ dry soil) } \\
\hline $\mathrm{Y}$ & $\mathrm{La}$ & $\mathrm{Ce}$ & $\operatorname{Pr}$ & $\mathrm{Nd}$ & $\mathrm{Sm}$ & $\mathrm{Eu}$ & $\mathrm{Gd}$ & $\mathrm{Tb}$ & Dy & Ho & $\mathrm{Er}$ & $\mathrm{Tm}$ & $\mathrm{Yb}$ & $\mathrm{Lu}$ & $\begin{array}{l}\text { Total } \\
\text { LREs }\end{array}$ & $\begin{array}{l}\text { Total } \\
\text { HREs }\end{array}$ & $\begin{array}{l}\text { Total } \\
\text { MREs }\end{array}$ \\
\hline 16.3 & 38.5 & 74.1 & 15.2 & 34.5 & 6.2 & 1.6 & 10 & 0.8 & 4.3 & 0.8 & 1.9 & 0.28 & 1.6 & 0.2 & 170.1 & 19.9 & 23.7 \\
\hline
\end{tabular}

following order: tap water, $0.01 \%$ nitric acid, tap water and distilled water. After the final washing step, plant samples were dried in an electric oven at $80{ }^{\circ} \mathrm{C}$ for $18 \mathrm{~h}$ to constant weight. The samples were then ground into powder for analysis.

\subsection{Measurement of concentrations of rare earths and heavy metals in plant samples}

Before digestion, all plant samples were dried in an electric oven at $80{ }^{\circ} \mathrm{C}$ for $6 \mathrm{~h}$ to remove moisture. A portion of dry plant sample (0.1-0.2 $\mathrm{g}$ ) was placed in a test tube and reacted with $4 \mathrm{ml}$ of nitric acid (conc., 70\%) overnight. After $24 \mathrm{~h}$, the samples were heated at $80{ }^{\circ} \mathrm{C}$ in an oil bath for $24 \mathrm{~h}$ and then cooled. A 3-ml aliquot of $30 \%$ $\mathrm{H}_{2} \mathrm{O}_{2}$ was added to each to complete the digestion and the final solutions were weighed.

The precision of this digestion method was evaluated by analyzing different kinds of plant samples in duplicate. It was found that the relative standard deviation in any plant sample was below $10 \%$ for the various individual rare earths, with the exception of Sc. The accuracy was checked by analysis of certified reference materials CRM 670 and CRM 0104 (aquatic plants supplied by the Community Bureau of Reference, The Netherlands); results deviated by less than $10 \%$ from certified values (Table 5). Hence, the above digestion procedure is suitable for the measurement of rare earths in plant samples by HR-ICP-MS. The heavy metal concentrations were also measured by HR-ICP-MS using the above method.

\subsection{Calculation and statistical analysis}

All data are presented on the basis of ovendried weight in plant materials. Logarithms of the chondrite-normalized abundance of individual rare earths in maize are plotted against the individual rare earths in the order of their atomic number. Chondritic normalization has two important functions. Firstly, it eliminates the abundance variations between odd and even atomic number elements, and secondly, it allows any fractionation of the rare earths group relative to chondritic meteorites to be identified. These meteorites are considered to represent the naturally occurring lanthanide abundance, undisturbed by geological and biological partitioning (Zhu, 1999). Logarithms of the chondrite-normalized abundance of individual rare earths in maize are expressed as $\log (\mathrm{REm} / \mathrm{REc})$, where REm is the concentration of individual rare earths in the maize and REc is the concentration of individual rare earths in the chondrite. Concentrations of individual rare earths in the chondrite are cited from Evensen et al. (1978). Significant

Table 5

Analytical results of certified reference materials by HR-ICPMS ( \pm standard deviation of four determinations)

\begin{tabular}{|c|c|c|c|c|}
\hline \multirow[t]{3}{*}{ Element } & \multicolumn{4}{|c|}{ Concentration ( $\mu \mathrm{g} \mathrm{g}^{-1}$ dry wt.) } \\
\hline & \multicolumn{2}{|l|}{ CRM670 } & \multicolumn{2}{|l|}{ CRM0104 } \\
\hline & Determined & Certified & Determined & Certified \\
\hline Sc & $212 \pm 72$ & $191 \pm 10$ & $69.4 \pm 18.3$ & $50.6 \pm 6.3$ \\
\hline $\mathrm{Y}$ & $412 \pm 6$ & $462 \pm 56$ & $139.8 \pm 5.7$ & $153.7 \pm 26.7$ \\
\hline $\mathrm{La}$ & $426 \pm 6$ & $487 \pm 20$ & $104.4 \pm 4.3$ & $128.9 \pm 14.3$ \\
\hline $\mathrm{Ce}$ & $914 \pm 9$ & $987 \pm 36$ & $236.8 \pm 10.0$ & $232.7 \pm 41.4$ \\
\hline $\operatorname{Pr}$ & $106 \pm 2$ & $121 \pm 8$ & $26.6 \pm 1.6$ & $31.8 \pm 0.7$ \\
\hline $\mathrm{Nd}$ & $441 \pm 8$ & $473 \pm 15$ & $115.1 \pm 5.8$ & $135.5 \pm 13.1$ \\
\hline $\mathrm{Sm}$ & $95.8 \pm 1.4$ & $94.2 \pm 6.2$ & $25.6 \pm 1.5$ & $28.5 \pm 2.4$ \\
\hline $\mathrm{Eu}$ & $23.7 \pm 1.0$ & $23.2 \pm 1.4$ & $7.28 \pm 0.46$ & $6.63 \pm 1.59$ \\
\hline $\mathrm{Gd}$ & $100.2 \pm 10.1$ & $97.8 \pm 7.4$ & $31.9 \pm 3.0$ & $31.6 \pm 4.0$ \\
\hline $\mathrm{Tb}$ & $13.6 \pm 0.3$ & $14.0 \pm 1.1$ & $4.0 \pm 0.2$ & $4.37 \pm 0.27$ \\
\hline Dy & $71.9 \pm 1.2$ & $78.9 \pm 6.3$ & $28.6 \pm 1.9$ & $32.8 \pm 1.2$ \\
\hline Ho & $14.5 \pm 0.2$ & $15.8 \pm 1.8$ & $4.9 \pm 0.2$ & $5.5 \pm 0.3$ \\
\hline $\mathrm{Er}$ & $38.8 \pm 0.9$ & $44.0 \pm 2.7$ & $13.6 \pm 0.6$ & $14.7 \pm 1.1$ \\
\hline $\mathrm{Tm}$ & $5.3 \pm 0.2$ & $5.7 \pm 0.6$ & $1.8 \pm 0.1$ & $2.3 \pm 0.3$ \\
\hline $\mathrm{Yb}$ & $32.81 \pm 2.0$ & $39.9 \pm 3.0$ & $11.1 \pm 0.5$ & $13.8 \pm 0.8$ \\
\hline $\mathrm{Lu}$ & $5.1 \pm 0.1$ & $6.3 \pm 0.5$ & $1.83 \pm 0.15$ & $2.32 \pm 0.33$ \\
\hline
\end{tabular}




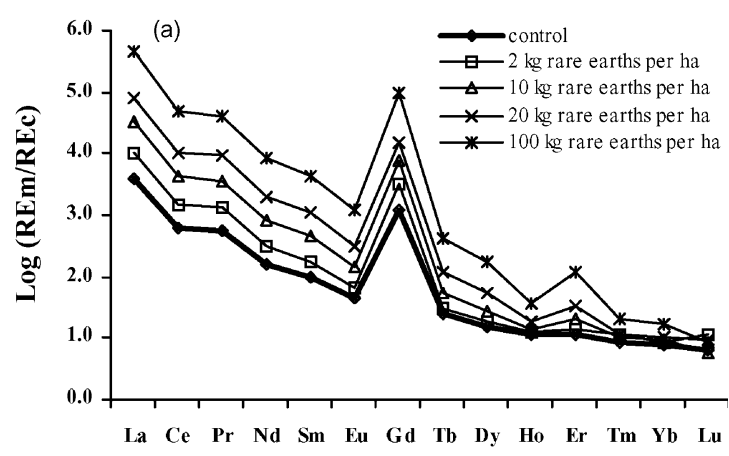

Atomic number

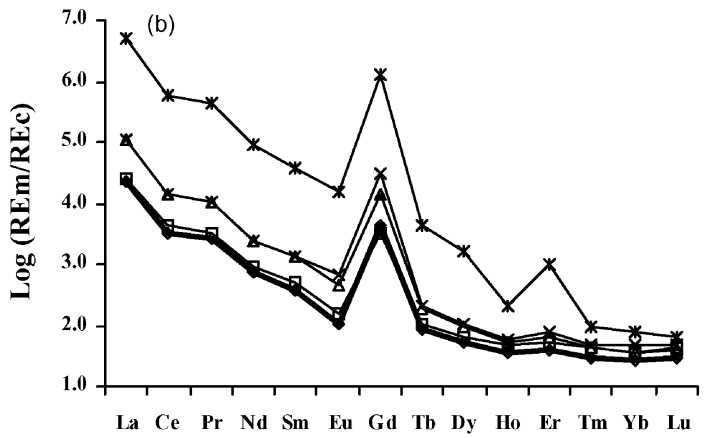

Atomic number

Fig. 1. Chondrite-normalized abundance of individual rare earths in (a) plant tops and (b) roots of maize 10 days after application of rare earths.

differences between means are analyzed by $t$-test using STATISTICA software for Windows (release 4.5 ) with a confidence interval of $95 \%$.

\section{Results and discussion}

\subsection{Distributions of rare earths in maize after different exposure periods}

Before application of rare earth-containing fertilizer, the variations in the concentrations of individual rare earths in all the plants grown on the 20 experimental plots were only minor, thereby indicating that the conditions before application of this fertilizer were the same on each plot.

Fig. 1a,b show the logarithms of the chondritenormalized abundance of individual rare earths in maize 10 days after application of the rare earths. Clearly, a substantial increase in the concentrations of individual rare earths occurred in the maize roots treated with more than $10 \mathrm{~kg}$ rare earths $\mathrm{ha}^{-1}$ (Fig. 1b), and even in the plant tops of maize treated with $2 \mathrm{~kg}$ rare earths ha ${ }^{-1}$ (Fig. 1a). The accumulation is much greater for the light than for the heavy rare earths. The concentration ratio of individual rare earths in the treated maize is calculated by dividing the concentration of individual rare earths in the treated maize by the concentration in the non-treated maize. At dosages less than $20 \mathrm{~kg}$ rare earths $\mathrm{ha}^{-1}$, the concentration ratios of most light rare earths and Gd in the plant tops were much greater than in the maize roots. Hence, under the experimental conditions used, the transport of light rare earths accumulated in the maize roots towards the plant tops was fast, particularly at low dosages of the applied rare earths. Ichihashi et al. (1992) also observed that translocation of rare earths to leaves might occur in a rapid manner.

The dose-dependent accumulative effects of individual rare earths in the maize roots at maturity stage (Fig. 2) were similar to those in plants 10 days after application of rare earths (Fig. 1b). However, at a dosage of $100 \mathrm{~kg}$ rare earths ha ${ }^{-1}$, an obvious reduction (e.g. for La, by over a factor of three) of the concentrations in the maize roots appeared at maturity stage. It was also observed that at the highest dose, a reduction in dry weight

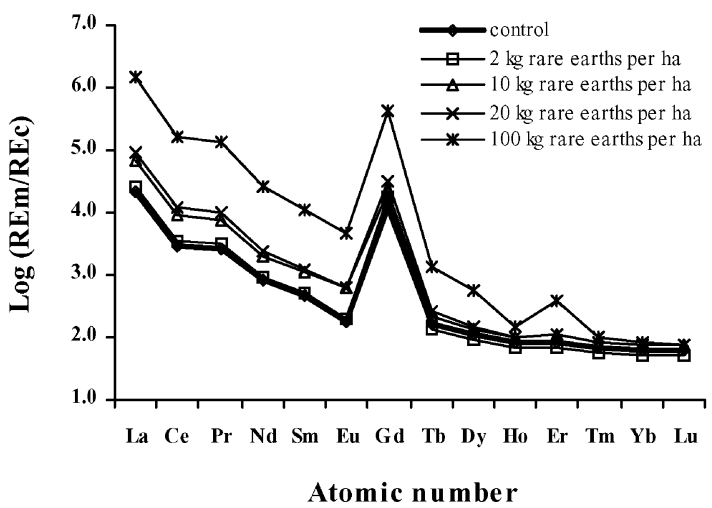

Fig. 2. Chondrite-normalized abundance of individual rare earths in the maize roots at maturity stage after application of rare earths. 


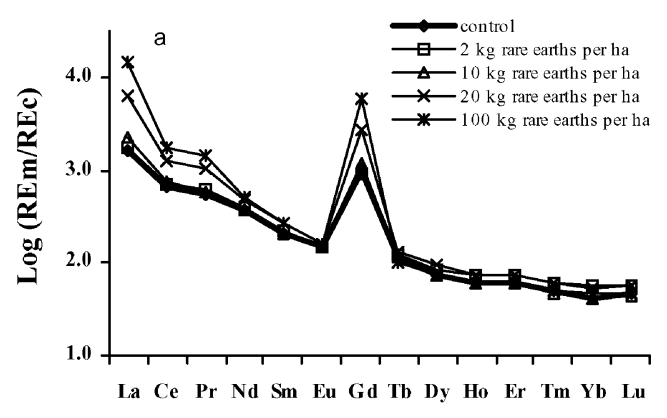

Atomic number

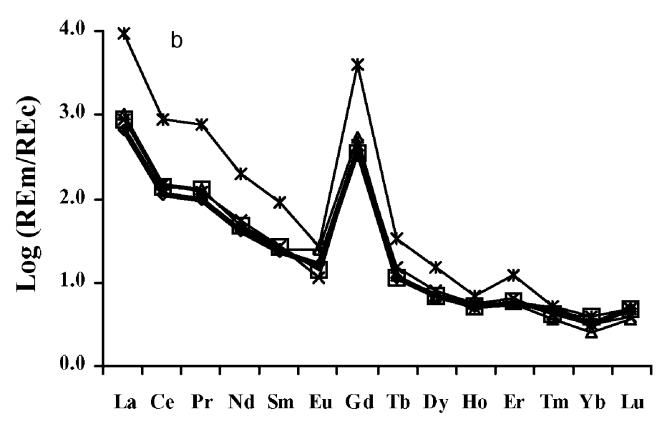

Atomic number

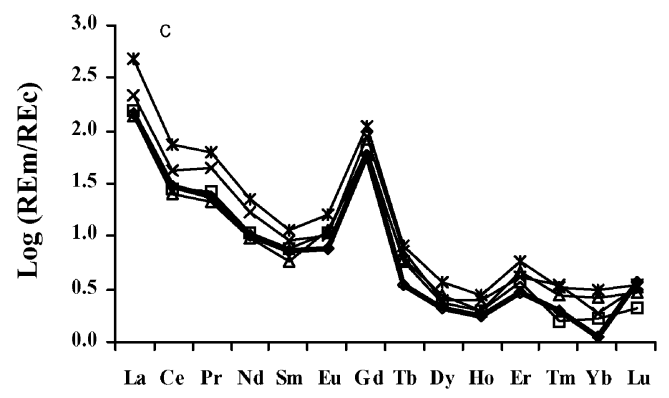

Atomic number

Fig. 3. Chondrite-normalized abundance of individual rare earths in the plant tops of maize at maturity stage after application of rare earths: (a) leaves; (b) stems; and (c) grains.

of the maize roots and the plant tops occurred (data not shown). Hence, at high dosages, rare earths are harmful to the growth of the roots. The capacity of rare earth uptake by the roots might be limited, mainly due to the self-protection mechanisms of the plants against adverse effects of rare earths (Diatloff et al., 1995).

Fig. 3 shows the logarithms of the chondritenormalized abundance of individual rare earths in the plant tops of maize (e.g. leaves, stems and grains) at maturity stage. From these patterns, it is evident that accumulative concentrations of individual rare earths in the plant tops gave no significant variations at dosages less than $10 \mathrm{~kg}$ rare earths $\mathrm{ha}^{-1}$. This is in contrast with the situation at 10 days after application, where substantially enhanced concentrations of individual rare earths in the plant tops of maize appeared, even at a dosage of $2 \mathrm{~kg}$ rare earths ha ${ }^{-1}$ (Fig. 1a). When the dosage of rare earths increased up to $20 \mathrm{~kg}$ $\mathrm{ha}^{-1}$, concentration ratios of $\mathrm{La}$ and $\mathrm{Ce}$, and thus of total amount of rare earths in the leaves, significantly increased $(P<0.05)$ compared to those at the dosage of $2 \mathrm{~kg} \mathrm{ha}^{-1}$. Hence, the distribution of individual rare earths in the plant tops of maize was variable after the application of rare earths. When the dosage of rare earths was less than $10 \mathrm{~kg}$ rare earths $\mathrm{ha}^{-1}$, no apparent accumulative concentrations of individual rare earths appeared in the maize grains. The concentrations of individual rare earths in the field-grown maize decreased in the order of roots $\gg$ leaves $>$ stems $>$ grains (Figs. 2 and 3).

During the maize growth period, the increase in the chondrite-normalized Gd abundance in the rare earth-treated maize clearly falls above the general trend (Figs. 1-3). It is almost equal to that of various light rare earths, although the concentrations of most light rare earths in the fertilizer (e.g. $\mathrm{La}, \mathrm{Ce}$ and $\mathrm{Pr}$ ) were more than 10-fold greater than the Gd concentration (Table 1). In addition, the background concentrations of for instance $\mathrm{La}$ and $\mathrm{Ce}$ in the soil are much greater relative to $\mathrm{Gd}$ (Table 4). It can therefore be concluded that under 


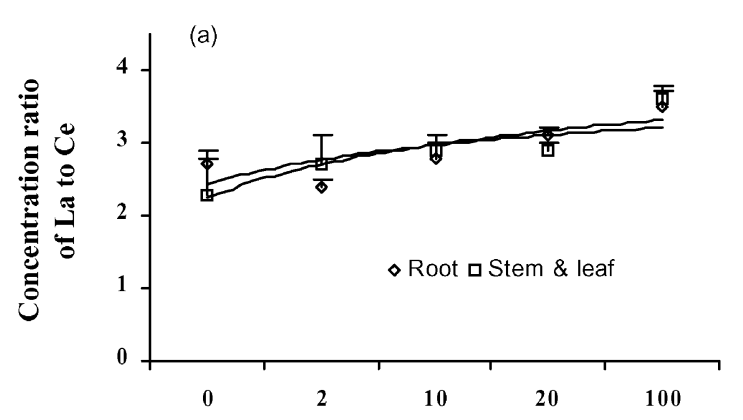

Added rare earths (kg rare earths $\mathrm{ha}^{-1}$ )

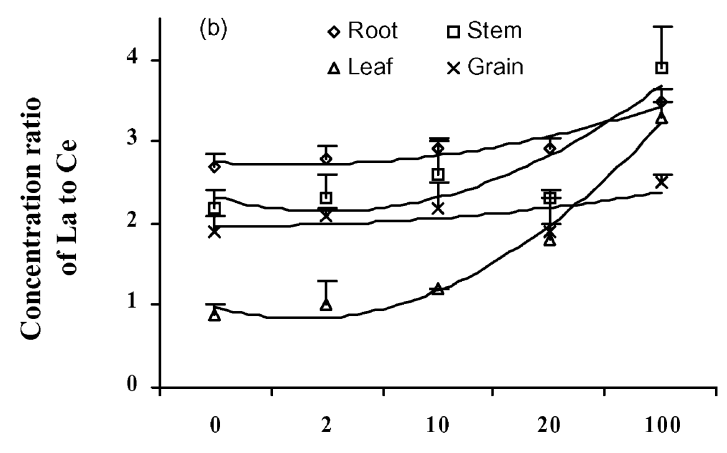

Added rare earths (kg rare earths $\left.\mathrm{ha}^{-1}\right)$

Fig. 4. Concentration ratio of $\mathrm{La} / \mathrm{Ce}$ in maize (a) at 10 days and (b) at maturity stage after application of rare earths.

the experimental conditions used, Gd in the soil can be easily taken up by maize roots and transferred from the roots to the plant tops. Although the reason for this so-called Gd anomaly (a large $\mathrm{Gd}$ enrichment in maize) is not clear, $\mathrm{Gd}$ accumulation might be considered as an important indicator for the fractionation of heavy rare earths in the plants.

\subsection{Selective accumulation of individual rare earths in maize}

At 10 days after the application of rare earths, the concentration ratio of $\mathrm{La} / \mathrm{Ce}$ in different parts of the maize had no apparent variation for any treatment; this ratio increased with increasing dosage of the rare earths applied (Fig. 4a). At a dosage of $100 \mathrm{~kg}$ rare earths $\mathrm{ha}^{-1}$, the concentra- tion ratio of $\mathrm{La} / \mathrm{Ce}$ in maize increased by up to more than 3.0, being larger than at the dosage of $2 \mathrm{~kg}$ rare earths ha- ${ }^{-1}$. As shown in Tables 1 and 4 , the concentration ratio of $\mathrm{La} / \mathrm{Ce}$ in the rare earth-containing fertilizer and in the soil is 0.6 and 0.5 , respectively. Therefore, during a short period after application of the rare earths, there is an apparent enrichment for $\mathrm{La}$ in field-grown maize compared to $\mathrm{Ce}$. At the maturity stage, the concentration ratio of $\mathrm{La} / \mathrm{Ce}$ in maize also increased with increasing dosage of the rare earths applied (Fig. 4b). This ratio value was the lowest in the leaves for the control (approx. 1.0), and was between approximately 2.0 and 3.5 at the highest dosage for all plant parts. Apparently, this was different from the similarity of the concentration ratio of $\mathrm{La} / \mathrm{Ce}$ in the maize as mentioned above (Fig. 4a).

As the maize plant grows, the transport of individual rare earths absorbed by the roots towards the plant tops might be limited, mainly due to plant protection mechanisms against adverse effects of rare earths (Diatloff et al., 1995). Brown et al. (1990) and Chang (1991) all reported that high bio-accumulated La concentration in plants efficiently enhances the permeability of cell membranes and disturbs their physiological functions. At high dosages $\left(100 \mathrm{~kg}\right.$ rare earths $\left.\mathrm{ha}^{-1}\right)$, rare earths could induce the presence of some yellow spots in old leaves during the maize growth period. Wu et al. (1983) also observed that the concentration of $\mathrm{La}$ in old leaves was much greater than in young ones. Hence, this phenomenon may reduce the transport of $\mathrm{La}$ accumulated in the roots towards the plant tops during the late period of maize growth.

During the maize growth period, the concentration ratio of $\mathrm{La} / \mathrm{Ce}$ in the roots showed no significant variations (Fig. 4a,b). When maize roots can absorb individual rare earths from the host soil, there is simultaneous transport of absorbed $\mathrm{La}$ towards the plant tops and exudation of the roots. Hence, under the experimental conditions used, selective accumulation of individual rare earths (e.g. $\mathrm{La}, \mathrm{Ce}$ ) in the maize roots seemed to be in dynamic equilibrium. 
Table 6

Concentration of heavy metals in the maize grains after application of rare earth-containing fertilizer

\begin{tabular}{|c|c|c|c|c|c|}
\hline \multirow[t]{3}{*}{ Element } & \multicolumn{5}{|c|}{ Heavy metal concentration ( $\mu \mathrm{g} \mathrm{g}^{-1}$ dry wt.) } \\
\hline & \multicolumn{5}{|c|}{ Dosage of rare earths added ( $\mathrm{kg}$ rare earths $\mathrm{ha}^{-1}$ ) } \\
\hline & 0 & 2 & 10 & 20 & 100 \\
\hline $\mathrm{Ca}$ & $54(2)$ & $58(7)$ & $42(15)$ & $42(10)$ & $54(11)$ \\
\hline $\mathrm{Cr}$ & $0.9(0.3)$ & $0.6(0.1)$ & $0.5(0.1)$ & $0.8(0.1)$ & $0.8(0.1)$ \\
\hline Mn & $8.3(0.9)$ & $7.4(0.9)$ & $6.6(2.4)$ & $7.3(0.7)$ & $7.3(0.9)$ \\
\hline Co & $0.01(0.0)$ & $0.01(0.0)$ & $0.01(0.0)$ & $0.01(0.0)$ & $0.01(0.0)$ \\
\hline $\mathrm{Ni}$ & $0.9(0.1)$ & $0.7(0.2)$ & $0.7(0.2)$ & $0.8(0.1)$ & $0.8(0.1)$ \\
\hline $\mathrm{Zn}$ & $11.4(2.1)^{\mathrm{a}}$ & $9.8(2.9)^{\mathrm{a}}$ & $10.2(2.1)^{\mathrm{a}}$ & $11.5(1.2)^{\mathrm{a}}$ & $5.8(1.2)^{\mathrm{b}}$ \\
\hline $\mathrm{Cu}$ & $6.8(1.9)$ & $4.1(1.0)$ & $5.3(2.3)$ & $6.2(1.0)$ & $6.5(0.5)$ \\
\hline Mo & $0.9(0.1)$ & $0.8(0.2)$ & $0.7(0.2)$ & $1.0(0.2)$ & $0.9(0.1)$ \\
\hline $\mathrm{Pb}$ & $0.2(0.1)$ & $0.1(0.0)$ & $0.1(0.0)$ & $0.2(0.1)$ & $0.2(0.0)$ \\
\hline
\end{tabular}

Within a row, means (standard deviations) followed by superscripts are significantly different $(P<0.05)$ by $t$-test.

\subsection{Concentrations of heavy metals in maize grains after application of rare earths}

Table 6 shows the concentrations of heavy metals in maize grains after application of rare earth-containing fertilizer. When the dosage of rare earths increased up to $100 \mathrm{~kg} \mathrm{ha}^{-1}$, a reduction of almost $50 \%$ in the concentration of $\mathrm{Zn}$ appeared in the grains. Although the rare earth-containing fertilizer contains a high concentration of $\mathrm{Pb}$ (Table 2), the variation in the $\mathrm{Pb}$ concentration in the grains was very minor after application of different dosages of this fertilizer. As shown in Table 6, we observed no apparent accumulation of other heavy metals in the maize grains. Because at present agricultural soils in China receive less than $0.23 \mathrm{~kg}$ rare earths $\mathrm{ha}^{-1}$ year $^{-1}$, the application of rare earth-containing fertilizers as base fertilizers can hardly affect the concentrations of heavy metals in maize grains in arable soil, even over a long period.

\section{Conclusions}

The concentrations of individual rare earths in a field-grown maize after application of rare earths decreased in the order of root $\gg$ leaf $>$ stem $>$ grain. During the maize growth period, selective accumulation of individual rare earths (e.g. La, Ce) in the maize roots seemed to be in dynamic equilibrium, and the distributions of these elements in the plant tops were variable. La is taken up selectively compared to Ce, by a factor of two-three. When the dosage of rare earths was less than $10 \mathrm{~kg}$ rare earths $\mathrm{ha}^{-1}$, no apparent accumulative concentrations of individual rare earths and heavy metals were observed in the maize grains. We conclude that the present dosage of rare earths $(<0.23 \mathrm{~kg}$ $\mathrm{ha}^{-1}$ year $^{-1}$ ) currently applied in China can hardly affect the safety of maize grains in arable soil, even over a long period.

\section{Acknowledgments}

This project was financially supported by the National Science Foundation of China (Grant No 29890280-2-3), by the Chinese Academy of Sciences (RCEES-KIP-9901) and by the Royal Netherlands Academy of Arts and Sciences (00CDP005). The Fengqiu Agro-Ecological Experimental Station of the Chinese Academy of Sciences (Grant No. 201605) and the K.C. Wong Education Foundation (Hong Kong) also financially aided this work.

\section{References}

Brown PH, Rathjen AH, Graham RD, Tribe DE. Rare earth elements in biological systems. In: Gschneidner Jr KA, Eyring L, editors. Handbook on the Physics and Chemistry of Rare Earths, vol. 13. Amsterdam: Elsevier, 1990. p. $423-$ 452.

Chang J. Effects of lanthanum on the permeability of root plasmalemma and the absorption and accumulation of nutri- 
ents in rice and wheat. Plant Physiol Commun 1991;27:1721.

Diatloff E, Smith FW, Asher CJ. Rare earth elements and plant growth: I. Effects of lanthanum and cerium on root elongation of corn and mungbean. J Plant Nutr 1995;18:19631976.

Evensen NM, Hamilton PJ, O'Nions RK. Rare earth abundances in chondritic meteorites. Geochim Cosmochim Acta 1978;42:1199-1212.

FAO. UNESCO Document D: Draft Definitions of Soil Units at High Level, 1982.

Guo BS. Rare Earth in Agriculture. Beijing: China Agriculture Science and Technology Press, 1988. p. 30-150.

Henke G. Activation analysis of rare earth elements in opium and cannabis samples. J Radioanal Nucl Chem 1977;39:6983.

Ichihashi H, Morita H, Tatsukawa R. Rare earth elements in naturally grown plants in relation to their variation in soils. Environ Pollut 1992;76:157-162.

John RD, Owen B, Andrew F, Louise MG, Malcolm SC, Peter W, Mark C. Atomic spectrometry update - environmental analysis. J Anal At Spectrom 1998;13:1-56.

Kim HT. Soil Sampling, Preparation and Analysis. New York: Marcel Dekker, 1995. p. 40-260.

Liu SJ, Wang LJ, Zhang S, Gao XJ, Wang YQ, Sun JX, Chen HM, Qiu HJ. Effect of long-term foliage-dressing rare earth elements on their distribution, accumulation and translocation in soil - spring wheat system. Chin J Appl Ecol 1997;8:55-58.

Miekeley N, Casartelli EA, Dotto RM. Concentration levels of rare earth elements and thorium in plants from the Morro do Ferro environment. J Radioanal Nucl Chem 1994;182:75-84.

Qi BZ, Gao WJ, Yang XL, Tian XY, Tian XW. The effects of rare earth elements on the growth and the absorption of partial mineral elements in maize seedlings. Chin J Agric Sci 1990;16:305-310.

Sun J, Zhao H, Wang Y. Study of the contents of trace rare earth elements and their distribution in wheat and rice samples. J Radioanal Nucl Chem 1994;179:377-383.

Velasco JR, Domingo LE, Lansangan AS, Sierra ZN. Cultural studies on coconut cadang-cadang: reaction of plants to the rare earths, thallium and certain soil samples. Philips J Coconut Stud 1979;4:1-5.

Volokh AA, Gorbunov AV, Gundorina SF, Revich BA, Frontasyeva MV, Chen SP. Phosphorus fertilizer production as a source of rare-earth elements pollution of the environment. Sci Total Environ 1990;95:141-148.

Wang $\mathrm{CH}$. Effect of rare element on mineral absorption and nitrogen metabolism of wheat. J Chin Rare Earth Soc 1988;6:71-74.

Wang YQ, Sun JX, Chen HM, Guo FQ. Determination of the contents and distribution characteristics of REE in natural plants by NAA. J Radioanal Nucl Chem 1997;219:99-103.

Wang Z, Liu DF, Lu P, Wang CX. Accumulation of rare earth elements in corn after agricultural application. J Environ Qual 2001;30:37-45.

Wen HY, Peng RZ, Chen XW. Application of rare earth compound fertilizer in some crops in central Yunnan. Chin Rare Earths 2000;21:50-54.

Wu ZM, Tang XK, Gao XX, Jiao K, Zhang MP. Studies on the effect of rare earth elements on the increase of yield in agriculture I. Preliminary studies on the distribution and content of rare earth elements in plants. J Chin Rare Earth Soc 1983;1:70-75.

Wyttenbach A, Furrer V, Schleppi P, Tobler L. Rare earth elements in soil and in soil-grown plants. Plant Soil 1998;199:267-273.

$\mathrm{Xu}$ XK. Application of the rare-earth fertilizers for agricultural sustainable development. Res Dev Resour Environ Ecol Network 1997;8:23-26.

Xu XK, Wang ZJ. Effect of lanthanum and mixtures of rare earths on ammonium oxidation and mineralization of nitrogen in soil. Eur J Soil Sci 2001;52:323-330.

Yu Z, Chen M. Rare Earth Elements and Their Application. Beijing: Metallurgical Industry Press, 1995. p. 25-150.

Zhang Y, Xiong B, Hu Y, Zhang Q, Wu J, Zhang J. Effect of ten-year RE application on content and distribution of rare earth elements in spring wheat. Chin Rare Earth 1993;14:40-44.

Zhu W. Advanced Inductively Coupled Plasma Mass Spectrometry Analysis of Rare Earth Elements: Environmental Application. Rotterdam: AA Balkema Publishers, 1999. p. 60-260. PhD dissertation, Technical University of Delft. 